\title{
СОСТОЯНИЕ КОММУНИКАТИВНОГО КОНТРОЛЯ У ОБУЧАЮЩИХСЯ ПО ДЕФЕКТОЛОГИЧЕСКИМ НАПРАВЛЕНИЯМ ПОДГОТОВКИ
}

\section{STATUS OF COMMUNICATION CONTROL AMONG STUDENTS IN SPECIAL AREAS OF TRAINING}

\section{Tyutyueva \\ T. Filyutina}

Summary: The article analyzes the educational standard of higher education and considers communicative competence, as one of the components of the competence of future specialists of defectological education. The authors analyze modern research and identify 4 components of the pedagogical task-situation: the target component, content-cognitive component, emotional and behavioral component, performance-predictive components, and represent the developed model of communicative activity in solving a problematic pedagogical situation. The article presents the results of a study of the levels of selfcontrol assessment in communication.

Keywords: communication, communication competence, communication control, students, special (defectological) education, model of communicative activity.

\author{
Тютюева Ирина Анатольевна \\ К.nсх.н., дочент, Шадринский государственный \\ педагогический университет \\ medvedeva452020@mail.ru \\ Филютина Татьяна Николаевна \\ К.n.н., доцент, Шадринский государственный \\ педагогический университет \\ filyutina1960@mail.ru
}

Аннотация: В статье анализируется образовательный стандарт высшего 0бразования и рассматривается коммуникативная компетентность, как одна из составляющих компетентностей будущих специалистов дефектологического образования. Авторы, анализируя современные исследования, выделяют 4 компонента педагогической задачи-ситуации: целевой компонент, содержательно-когнитивный компонент, эмоционально-поведенческий компонент, результативно-прогностический компоненты и представляют разработанную модель коммуникативной деятельности в решении проблемной педагогической ситуации. В статье представлены результаты исследования уровней оценки самоконтроля в общении.

Ключевые слова: коммуникация, коммуникативная компетенция, коммуникативный контроль, студенты, специальное (дефектологическое) образование, модель коммуникативной деятельности.

Актуальность исследования коммуникативной компетенции начиная с работ Д. Хаймса. Д. Хаймс рассматривал коммуникативную компетенцию как способность быть участникам речевой деятельности. М. Кэналь, М. Свейн - считают ее основой системы знаний и навыков, необходимых для осуществления коммуникации [3].

В.Ю. Асадчих рассматривает коммуникативную компетентность как интегративное качество личности, В котором находит проявление совокупности лингвистического, психологического, социального компонентов, являющееся результатом рефлексивного диалогического взаимодействия обучающихся и педагогов в условиях личностно - развивающей образовательной среды [1].

М.А. Чошанов предлагает универсальную «формулу компетентности» включающую три компонента: мобильность знания, гибкость метода, критичность мышления. Эти компоненты отражают уровень минимальной компетентности, медиальной и полной [2].

Компетенция - это совокупность взаимосвязанных качеств личности (знаний, умений, навыков, способов деятельности), которые являются заданными к опреде- 
ленному кругу предметов и процессов и необходимыми для качественного продуктивного действия по отношению к ним [12]. Компетентность - владение человеком соответствующей компетенцией, содержащее его личное отношение к предмету деятельности [12].

Таким образом, коммуникативная компетенция - это объективная философская и педагогическая категория, а коммуникативная компетентность - субъектная личностная категория включающая определенный объем знаний, умений и навыков, которые человек присвоил и продолжает осваивать, и забирать как эффективные компоненты профессиональной деятельности.

Исходя из этих общих подходов, мы опираемся на трактовку коммуникативной компетенции Н.В. Соломиной, как «конгломерирующую форму компетенций, способную интегрировать более простые типы компетенций (языковую, речевую, прагматическую, предметную, культурную, лексикографическую, стратегическую, социолингвистическую, цивилизационную и т.д.)» [13, с.172].

В психолого-педагогической литературе в сходном контексте исследуются:

- «Коммуникативный потенциал у будущих педагогов в ВУЗе» (Л.Л. Лашкова, И.В. Резанович [6]).

- «Методы коммуникативной подготовки студентов на основе диагностики уровня коммуникабельности, типа характера» (О.А. Светлякова [8]).

- «Проблемы формирования навыков корпоративной культуры у студентов (В.Я. Жукова, Н.А. Туранина [10]).

- «Средства развития профессиональной рефлексии педагогов» (О.А. Шиян, А.Н. Якшина, С.А. Зададаев, Т.Н. Ле-ван [13]).

На основе анализа образовательного стандарта высшего образования республики Белорусь (СТБ ИСО 9000 2006), М.Л. Кривуть рассматривает коммуникативную компетентность «как много-компонентное образование, структурно-образующими компонентами каждого являются академические (АК), социально-личностные (СЛК) и профессиональные компетенции (ПК) [5].

AK - владение методологией и терминологией отдельной области знаний, понимание действующих в ней системных взаимосвязей, а также способность использовать в решении практических задач;

СЛК - готовность и способность целесообразно действовать в соответствии с требованиями реальной педагогической ситуации;

ПК - совокупность компетенций, относящихся к самому человеку как к личности с другими людьми группой и обществом» (М.Л. Кривуть, с. 198).
Мы проанализировали федеральный государственный образовательный стандарт высшего образования магистратура по направлению подготовки 44.04.03 Специальное (дефектологическое) образование мы пришли к выводу: данная компетенция (ПК -1) связана со следующими компетенциями: готовность к саморазвитию, самореализации, использованию творческого потенциала (ОК-3); готовность к коммуникации в устной и письменной формах на русском и иностранном языках для решения задач профессиональной деятельности (ОПК-1); способность демонстрировать знания фундаментальных и прикладных дисциплин магистерской программы, осознавать основные проблемы своей предметной области (ОПК-2); готовность к самостоятельному освоению и применению новых методов и технологий исследования (ОПК-3); способность осуществлять профессиональное и личностное самообразование, проектировать дальнейший образовательный маршрут и профессиональную карьеру (ОПК-5).

Компетенция ПК-1 обусловлена профилем «Дефектология» и необходима для формирования профессиональных компетенций ОК и ОПК, определенных ФГОС ВО. В частности, она способствует формированию компетенции: способностью к проектированию индивидуальных маршрутов развития, образования, социальной адаптации и интеграции лиц с ОВЗ на основе результатов психолого-педагогического изучения лиц с ОВ3 (ПК-2); способностью к проектированию коррекционно-образовательного пространства и разработке методического обеспечения с использованием информационных технологий (ПК-3); готовностью к обеспечению взаимодействия работников сфер образования, здравоохранения и социальной защиты при решении актуальных коррекционно-педагогических задач (ПК-4). Сформированная компетенция ПК-1 позволит выпускнику осуществлять такие профессиональные задачи, как осознанный и аргументированный с теоретической и методической точек зрения выбор психолого-педагогических технологий для работы с детьми с ОВ3.

Профессиональная педагогическая коммуникация затрагивает все сферы психики специалиста дефектологического направления: познавательную, поведенческую, личностную, эмоционально-волевую. Коммуникация учителя - дефектолога строится с разными объектами: дети с разными нарушениями в развитии и поведении; родители этих детей, лица их замещающие; педагогические работники разного возраста и с разным опытом работы; профессиональные коллективы и методические объединения; менеджеры в системе образования. Такое широкое коммуникативное поле требует знания содержания преподаваемых дисциплин. Формирование данной комментенции предполагает наличие мобильных знаний и гибкость их применения из ряда дисциплин психолого-педагогического блока: «Общая и 
возрастная психология», «Психоло-педагогическое консультирвоание, «Психология делогово общения», «Психолингвистика», «Организация образовательно-коррекционной работы для лиц с ОВ3», «Современные методы психолого-педагогической диагностики», «Лингвистические проблемы специальной педагогики и психологии», «Консультирование родителей (законных представителей) детей с ОВЗ», «Консультирование педагогов образовательных организаций», «Управленческая деятельность в специальном образовании», «Менеджмент в специальном образовании», «Современные информационно-коммуникационные технологии», «Организация работы с родителями имеющими детей с ОВЗ».

Моделированию коммуникативной деятельности посвящено много современных исследований. Так, И.Н. Корзенникова [4], она исследует три ступени становления межкультурной коммуникативной компетенции. На второй ступени ключевое положение занимает коммуникативная компетенция, включающая многочисленные составляющие (лингвистическая, социолингвистическая, дискурсивная, стратегическая, социокультурная, социальная, деятельностная) и закономерно-влияющая на картину мира и коммуникацию. Автор считает, что коммуникативная компетентность - как совокупность компетенций позволяющий накопить коммуникативный потенциал и способ выражения мыслей закономерно влияет на картину мира личности и на коммуникативную деятельность.
Следуя дальше логике анализа структуры коммуникативной деятельности, мы считаем, что в решении любой педагогической задачи-ситуации присутствуют 4 компонента:

1. Целевой компонент.

2. Содержательно-когнитивный компонент.

3. Эмоционально-поведенческий компонент.

4. Результативно-прогностический компоненты.

Выделяя данные компоненты, мы опираемся на инклюзивный, субъектно-деятельностный, персональный подходы внутри приоритетной в настоящее время личностно-ориентированной парадигмы образования [10].

Комментируя модель важно подчеркнуть, что объект коммуникации (дети с ОВ3, родитель (мама, папа, бабушка дедушка, опеукн), специалисты работающие с детьми с ОВЗ воспитатель продленного дня, классный руководитель, завуч, психолог, социальный педагог, директор, учителя предметники) коммуникации определает частные задачи и специальное содержание каждого компонента.

1. Целевой компонент данной модели является ведущим. Он определяет общую цель и конкретные задачи во всех структурных частях модели. Специалист дефектолог является участником и наблюдателем за конкретными педагогическими ситуациями, у него формируется взгяд на сущность, причины, эмоциональную окраску, педагогиче-

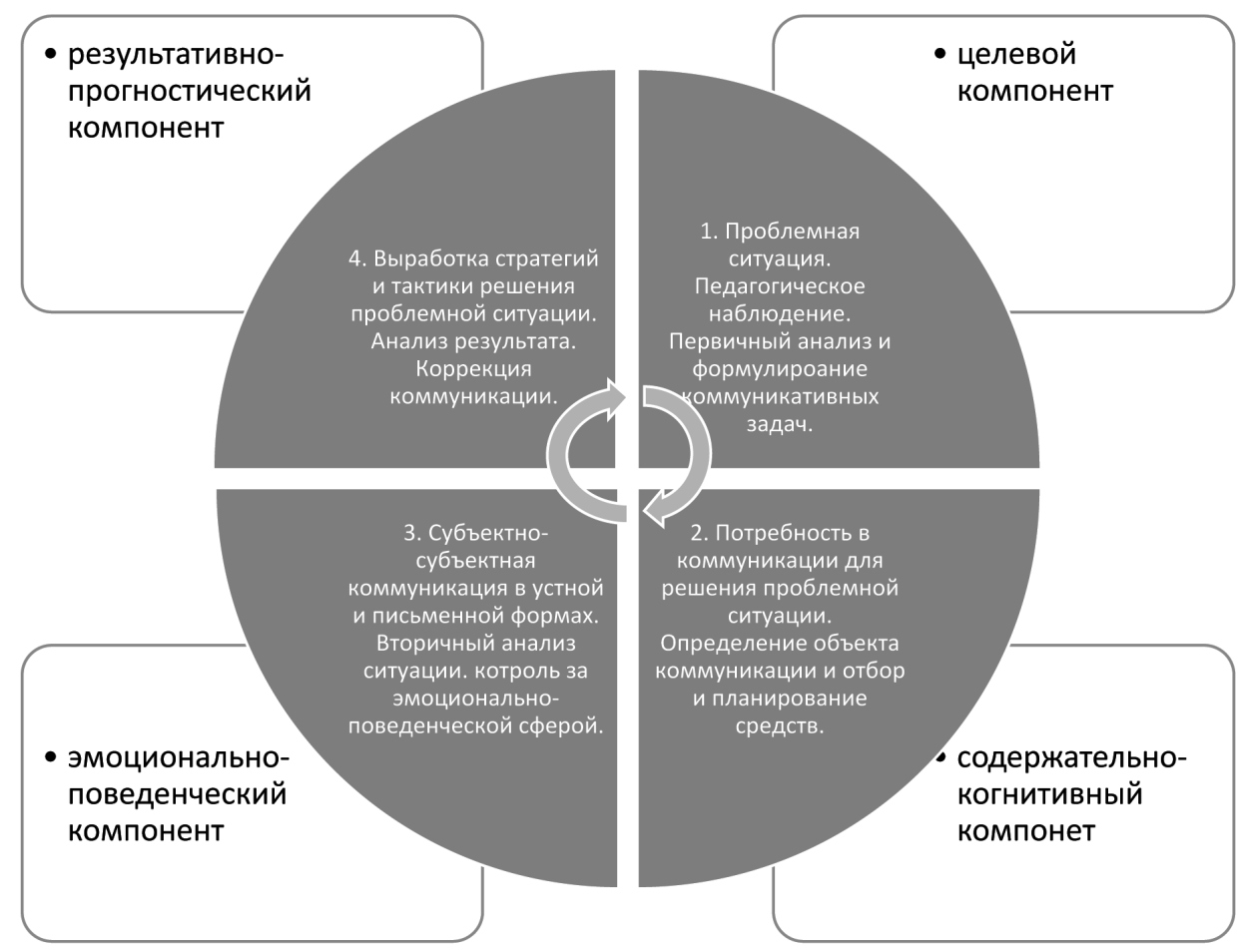

Рис.1. Модель коммуникативной деятельности в решении проблемной педагогической ситуации 
ская оценка и анализ данной ситуации.

2. Содержательно-когнитивный компонент модели определяет техники консультативного процесса в зависимости от психологической платформы консультирования с опорой на знания возрастной, специальной и педагогической психологии, психологии семьи. Важно спланировать коммуникацию в комфортном пространстве и в удобное время. Коммуникативное взаимодействие между специалистом-дефектологом и ребенком с ОВ3, родителями, коллегами может осуществляться как в классическом варианте , в форме беесды , так и в других активных формах коммуникации.

3. Эмоционально-поведенческий компонент, предполагает субъект-субъектное взаимодействие специалиста-дефектолога с участниками образовательного процесса на основе гуманистического подхода и толератности к людям с OB3, лицам другой рассы, национальности, вероисповедения, веры, культуры и педагога и вторичный ананлиз двумерного измерения проблемы.

4. Результативно-прогностический компонент предполагает анализ результата коммуникации и совметстную стратегию и тактику поведения и деятельности на определенный отрезок времени, и соответственно планируется следующая интеракция.

Процесс коммуникативной деятельности в решении проблемной педагогической ситуации-задачи динамичен и развивается по спирали выходя каждый раз на боллее высокий уровень коммуникации. Согласно исследованию А.В. Хуторского и Л.Н. Хуторской были выделены четыре уровня компетентности при решении задачи - ситуации. Для каждого уровня решения задачи - ситуации выделяются способы решения (один способ и разные) и количество вариантов решения (одно верное решение и несколько верных решений). Опираясь на данный подход мы предполагаем, что в отдель- ных коммуникативных ситуациях могут быть неверные решения. В этом проявляется действие универсального философского закона «единство и борьба противоположностей».

Целью нашего исследования являлось оценить самоконтроль в общении у студентов заочного отделения по направлению подготовки «Логопедия». В исследовании приняли участие 80 испытуемых 3 курса, 20 человек 4 курса. Для оценки самоконтроля в общении использовалась методика М. Снайдера «Методика диагностики оценки самоконтроля в общении».

В результате обработки полученных данных испытуемые были распределены на три уровня коммуникативного контроля (низкий, средний, высокий). Данные представлены на рисунке № 2. Распределение испытуемых по уровням оценки самоконтроля в общении.

Как видно из диаграммы, что больше половины выборки испытуемых 3 курса, что составляет - 55 \%, имеют низкий уровень самоконтроля в общении. Для данного уровня присуще следующие показатели: личность характеризуется высоким уровнем импульсивности в общении и взаимодействии с окружающими, низкой дифференцированностью поведения, что вызывает раскованность во взаимодействии с партнерами по общению. Имеет устойчивое «Я». Поведение таких людей устойчиво, и они не считают нужным менять его в зависимости от ситуации. Способны к искреннему самораскрытию в общении, прямолинейны. Из рисунка можно увидеть следующее, что к 4 курсу уровень оценки самоконтроля в общении снижается, что говорит об овладении в процессе обучения коммуникативными навыками.

Испытуемые со средним уровнем самоконтроля в общении составляют 31\% выборки 3 курса характеризуются сдержанностью и низкой эмоциональностью в общении, искренностью и непосредственностью при взаимодействии с окружающими. Можно отметить инте-

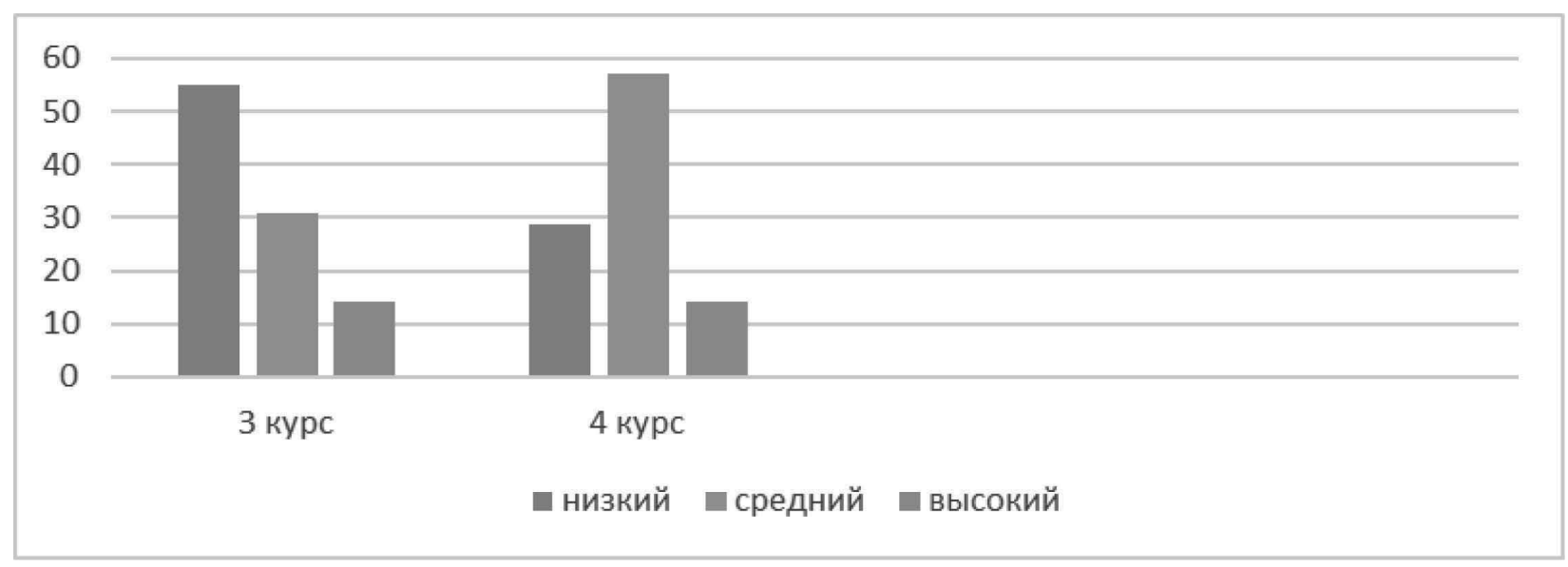

Рис 2. Распределение испытуемых по уровням оценки самоконтроля в общении, \% 
ресный факт, что к 4 курсу данный уровень увеличивается, что говорит о своеобразных особенностях в общении.

Будущие педагоги, которые будут работать с детьми с ОВ3 продемонстрировали также высокий уровень самоконтроля в общении, что составило - 14\% выборки. Личность характеризуется достаточно высоким уровнем эмоциональной сдержанности и контроля своего поведения при взаимодействии с окружающими. Такие люди постоянно следят за собой, обладают позицией «Я такой, какой я есть в данный момент», гибко реагируют на изменение ситуации, легко входят в любую роль, хорошо чувствуют и зачастую способны предвидеть впечатление, которое произведут на окружающих.

Таким образом, результаты диагностики показывают:

1. Будущие специалисты инклюзивной системы образования в большинстве демонстрируют низкий (51 \% и средний (31\%) уровень самоконтроля в общении, что не способствует эффективности коммуникативного взаимодействия и зачастую накапливает отрицательные эмоции у участников образовательного процесса и приводит к конфликтным ситуациям.

2. Формирования коммуникативной компетентности - длительный процесс и не решается быстро. Обусловлена большим количеством факторов влияющих на коммуникацию (среда в которой воспитывался, жил, обучался, приобрел ценности и смысл жизни), условий (качество и опыт семейного, дошкольного и школьного, вузовского межкультурного общения) и закономерностей общих (этические нормы поведения и общения в социуме) и профессиональных (диктуемых нормативно-правовыми документами, развитием самопроцессов, в том числе и самоконтроля в общении).

3. Перед специалистами стоят задачи преодоление у студентов импульсивности в общении детьми с ОВ3, родителями, коллегами. Формирование гибкого дифференцированного поведения при взаимодействии с партнерами по общению. Переключение с устойчивого «Я» на субъект общения и состояния его психики в данный момент. Формирование толерантного отношения и эмпатийного общения и нацеливание воспитательного и развивающего ресурса в зону ближайшего развития ребенка.

4. В представленной нами «Модели коммуникативной деятельности в решении проблемной педагогической ситуации» (рис. № 1.) специалисты могут застревать на одном из компонентов (когнитивном или эмоционально-волевом компонете) это отрицательно сказывается на общем резузультате коммуникации (обида, конфликт, устранение от деятельности, пассивный протест). Отрицательный результат влияет на деятельность обучающихся, на результат общения, на профессиональные качества, на профессионаый опыт и статус педагога, на весь миктроклимат образовательной организации. Отбор средств и техник коммуникации должен опиратся на законы здоровьесбережения всех участников образовательного процесса.

\section{ЛИТЕРАТУРА}

1. Асадчих В.Ю. Управление процессом формирования коммуникативной компетентности старшеклассников автореф. Дис... канд. пед. наук. 13.00.01 /В.Ю. Асадчих. - Курск, 2009. - 19 с.

2. Князева В.В. Педагогика: словарь научных терминов // В.В. Князева. - М.: Вузовская книга, 2009. - С. 318.

3. Комарова И.И. Будущее дошкольного образования в эпоху циффровизации // Современное дошкольного образование - 2018. № 8 (90). С. 16-25.

4. Корзенникова И.Н. Особенности процесса формирования межкультурной коммуникативной компетентности // Педагогическое образование в России. 2018. - № 9. - С. $13-24$.

5. Кривуть, М.Л. Креатив-технологии в формировании коммуникативной компетентности педагога инклюзивного образования // Психология и педагогика творчества. С. $197-200$

6. Лашкова Л.Л. Развитие коммуникативного потенциала у будущего педагога в ВУзе // Л.Л. Лашкова, И.В. Резанович., - М. : Гуманитар. Изд-во ВЛАДОС, 2011. -340 c.

7. Назаревич 0.С. Развитие креативности как составлющей готовности будущих специалистов дефектологических специальностей к работе в условиях инклюзии // Качество жизни детей и молодых людей с инвалидностью: между видением и реальностью. // Матер. Всероссийской научно-практической конференции. Под редакцией Л.М. Волосниковой, Н.Н. Малярчук, А.В. Спириной. 2019 Изд-во: Тюменский гос. ун-т. - Тюмень, 2019. С. 117 -124

8. Светлякова, 0. А. Коммуникативная подготовка студентов на основе личностно ориентированного обучения [Текст] / 0. A. Светлякова // Alma mater: Вестник высшей школы : науч. журн. — 2016. — N 7. — C. 115-120 . — ISSN 0321-0383

9. Соломина, Н. В. Интертекстуальная компетенция как составляющая коммуникативной компетенции / Н. В. Соломина // Коммуникативная культура современника: проблемы и перспективы исследования: материалы I Всероссийской научно-практической конференции; под ред. Т. А. Федосеевой. Новокузнецк: РИО КузГПА, 2007. -244 с. -С.172-176.

10. Туранина, Н. А. Формирование коммуникативной компетентности студента как составляющей корпоративной культуры [Текст] / Н. А. Туранина, Я. В. 
Жукова // Среднее профессиональное образование. — 2012. — № 5. - С. 30-31. — Библиогр.: с. 31

11. Филютина Т.Н., Тютюева И.А. Реализация методологических подходов при подготовке студентов с ОВЗ к профессиональным конкурсам Педагогическое образование 2020 № 10

12. Хуторской А.В., Хуторская Л.Н. Компетентность как дидактическое понятие: содержание, структура и модели конструирования // Проектирование и организация самостоятельной работы студентов в контексте компетентностного подхода: Межвузовский сб. науч. тр. / под ре. А.А. Орлова. - Тула: Изд-во Тул. Гос. пед. ун-та им. Л.Н. толстого, 2008. - Вып. 1. - С. $117-137$.

13. Шиян 0.А., Якшина А.Н., Зададаев С.А., Ле-ван Т.Н. Средства развития профессиональной рефлексии педагогов дошкольного образования // Современное дошкольное образования 2019. - № 4. - № 14

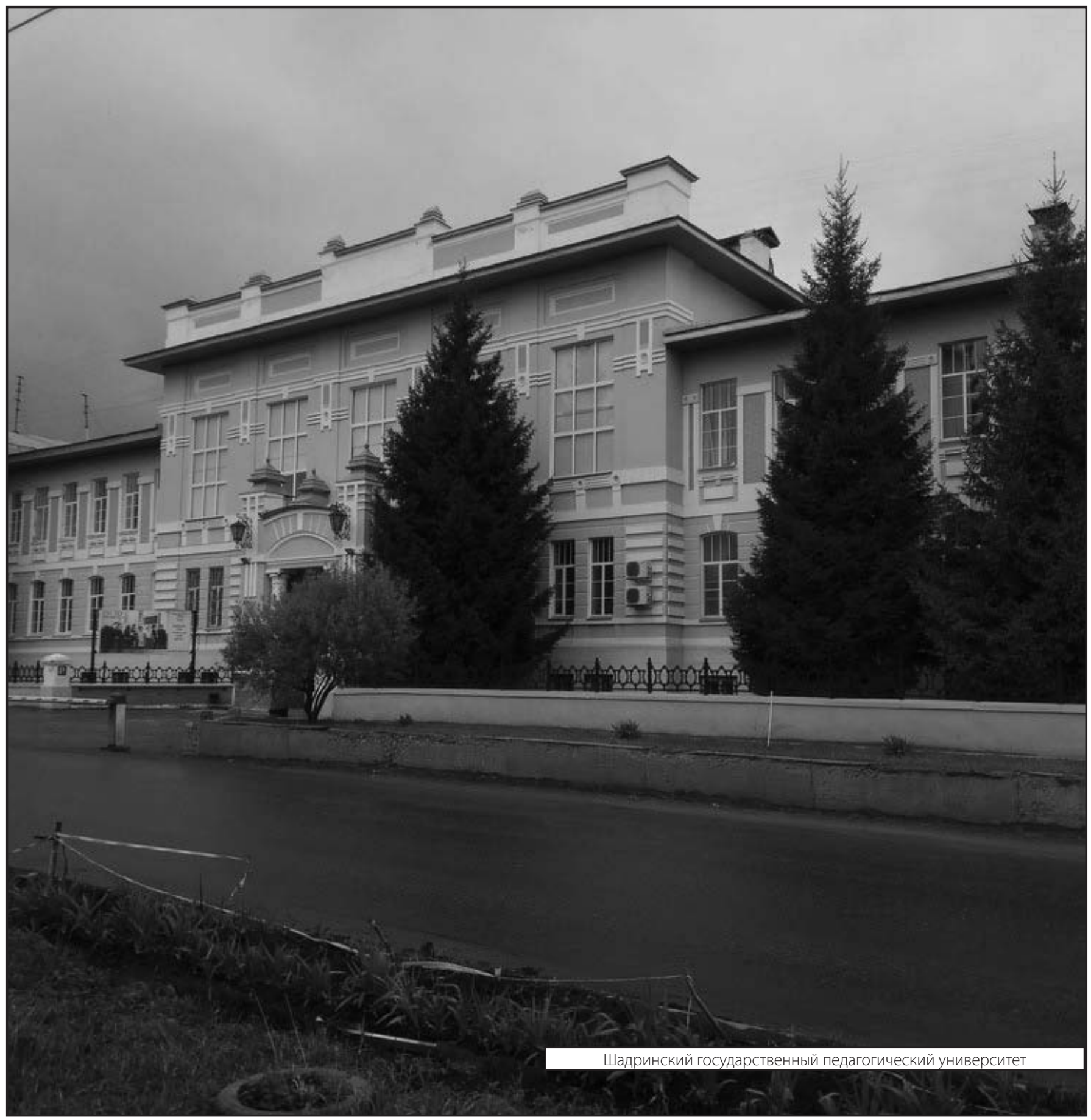

